\title{
PIE News. A public design project toward commonfare
}

Francesco Botto

Maurizio Teli
FBK CREATE-NET Research Center, Italy

Corresponding Author.

fbotto@,fbk.eu

Madeira Interactive Technology Institute, Portugal maurizio.teli@m-iti.org

The new poor are a group of people composed by precarious workers, working poor, NEETs, and people left behind by the safety nets, accounting for approximately $25 \%$ of the European population. Commonfare is a new collaborative form of welfare provision based on equitable governance and grassroots democracy, entailing the involvement of diverse stakeholders to facilitate the bottom-up emergence of collective practices tackling the needs of the new poor. The paper mainly describes the concepts and building blocks of the PIE News project, a public design project which started in July 2016 with the aim to foster the emergence of commonfare as an alternative model to satisfy the needs of the new poor. PIE news leverages on 3 pilots (Italy, Croatia, Netherlands) with grassroots organizations in order to create a commonfare model through the development of a Collective Awareness Platform and a Digital Currency tool. The network supporting the project is constituted by organizations that account for approximately one-hundred thousand social media contacts. These organizations include ethical banking, networks of associations, activists for basic income, and many others. Finally, the paper briefly presents some results of the project at one year from its start.

Keywords: New poor, Commonfare, Public design, Collective awareness, Digital currency

Botto, F., Teli, M. (2017). PIE News. A public design project toward commonfare. The Journal of Community Informatics, 13(2), 87-105.

Date submitted: 2017-03-28. Date accepted: 2017-08-21.

Copyright (C), 2017 (the author as stated). Licensed under the Creative Commons AttributionNonCommercial-ShareAlike 2.5. Available at: www.ci-journal.net/index.php/ciej/article/view/1383 


\section{Introduction}

Across Europe there are social groups that are particularly at risk of poverty or social exclusion, and the European Commission identifies them as "women, young people, people living in single-parent households, lower educated people and migrants." (Eurostat, 2015). However, due to the enduring crisis conditions and the insufficiency of social policies in some EU countries (Cantillon, 2011), new forms of poverty have turned up - also triggered by transformations in the labour market that have accelerated during the crisis (Jenkins et al., 2012). Indeed, before the crisis, the most common factor triggering a situation of poverty was the exclusion from the labour market and hence a lack of income. Today there are several other factors contributing to the rise of the new poor (Bauman, 2004) condition including: the precarious job conditions; and the increase of working poors, young people not involved in both employment or training, and people who do not qualify for social safety nets.

The main objective of the PIE News project - 3 years EC-H2020-ICT-2015 funded since July 2016 - is to sustain the emergence of the commonfare as a new and collaborative economic model, connecting the new poor and relevant stakeholders like public administrations, advocacy organizations, and ethical financing organizations. Such general objective will be achieved relieving the PIE (Poverty, lack of Income and unEmployment) conditions people may experience through: 1) the provision, aggregation and sharing of useful information; 2) the support to sharing existing good practices on their daily efforts to cope with such conditions, and 3) supporting the strengthening at the European level of the most promising of these practices.

The project is deeply involved in community informatics because of the involved technology and methodology. PIE News foresees the adoption of information technologies as a way to help people facing their economic problems, therefore the consortium decided for the development and adoption during the project timeline of a collective awareness platform (CAP), including a reputation system, and a digital currency component.

The three pilots will be led by community management institutions that are already deeply involved with grassroots' associations and working poor individuals in Netherlands, Croatia and Italy. PIE News technologies will be designed participatory and developed with the help of people using a public design approach.

This paper describes the building blocks of the PIE News project in its very early phase, aiming to: (1) contextualise the novel condition of poverty that is affecting Europe in the last years; (2) present commonfare as a possible part of the solution; (3) describe the technologies and methodologies adopted in order to participatory involve new poor in a tentative of - establishing the commonfare, with two concrete user scenarios; and (4) assumptions and plans for making sustainable innovation. Finally, the paper briefly describes some early results of the project after one year of activity. 


\section{Theory}

\section{New poor}

In the European Union, more than 122 million of people (about $24 \%$ of the population) are at risk of poverty or social exclusion (Eurostat, 2015). Even after social transfers, $17 \%$ of the population remain in such condition. Among them, 9\% of the European population is severely materially deprived that is, for example, being unable to pay the bills or face unexpected expenses.

A series of factors are actually triggering a novel condition of poverty in Europe. A first relevant factor is the type of labour contracts and the spread of precarious conditions (Standing, 2013; Fumagalli, 2013), which lead to discontinuous income and unstable jobs. Current research also shows that women, young people and migrants are the groups more experiencing precarious conditions (McKay, Jefferys, Paraksevopoulou, \& Keles, 2012). A second factor triggering poverty in many European countries, are the decreasing wages characterizing the last years, even for stable workers. Wages have not been able to maintain purchasing power and, as a result, the amount of working poor has quickly been rising in Europe (Fraser, Gutierrez, \& Pena-Casas, 2011). A third factor is linked to the deteriorating labour market conditions for early entrants (e.g. unreported jobs, unpaid jobs) and early school leave (e.g. school dropout) which together have been contributing to the emergence of the phenomenon of NEETs, that are young people Not in Education, Employment or Training (Eurofound, 2012; Fumagalli, 2013). Last, a fourth factor is the growing number of people who do not - or no longer qualify for social safety nets because of the enduring crisis and the declining adequacy over time of those nets (such as unemployment benefits and social assistance, e.g. Nelson, 2013).

We will refer to these four social groups as the new poor (Bauman, 2004), as the forms of poverty which are triggered by these factors differ from the ones traditionally related to a lack of employment. In fact, the people experiencing new forms of poverty do not necessarily need to be outside the labour market although a prolonged expulsion from the labour market or the educational system may cause long-term marginalization.

Unfortunately, the number of new poor in Europe is still unknown. One of the objectives of PIE News is to get an image of this phenomenon while collaborating with people experiencing this condition.

\section{Commonfare}

The main needs of new poor relate to the access to a primary income but also to a cluster of social services, which has to do with housing, training, or mobility. Addressing these needs requires novel and unconventional approaches, like housesharing, peer-to-peer training, ride-sharing, or access to information about skill acquisition. These novel approaches can beneficially be supported and fostered with digital technologies, siding the conventional welfare state approaches and promoting the emergence of new economic models, like the commonfare. 
Commonfare is an emerging direction for thinking and practicing welfare provision, and the concept has been elaborated in recent years by researchers and activists interested in alternative ways to overcome the European crisis (Provisional University, 2014, Fumagalli 2015a, Fumagalli 2015b). With the reduction of vital welfare services and the rise of poverty caused by austerity in some European areas, it has been noticed that precarious conditions caused by shortage of "common goods" for poor population could be overcome by initiatives concerning "self-managed commons". In simple words: selfmanaged commons can take many forms, always situated and negotiated between a particular community and the resources they depend on. It requests equitable governance and grassroots democracy as well as the involvement of stakeholders in order to facilitate the emergence of good collective practices: the welfare of common is therefore a form of welfare provision supporting such collective practices (Fumagalli and Lucarelli, 2015).

The concept of Commonfare is not still academically mature and it grounds on theoretical and practical reasoning on "cognitive capitalism" and austerity politics in Europe (Fumagalli, 2008; Vercellone, 2014). One of the PIE News objectives is to develop this concept from a theoretical/activists' understanding to a design-oriented and empirically-grounded research one.

\section{Public design}

PIE News relies on design methodologies to involve directly the target social groups in shaping the PIE News platform, in order to successfully adapt the potential digital tools available into effective instruments for people empowerment. To do that, the consortium relies upon the design tradition known as Participatory Design (PD), originated in Scandinavia in the " $70 \mathrm{~s}$ of the last century, to include directly the perspective of the future users into the technology design. PD is a form of co-design strongly oriented toward users' empowerment, both as a general social goal as well as during the design process of the technologies that will affect their lives (Simonsen \& Robertson, 2012).

Recent developments of PD referred to as community-based participatory design (DiSalvo, Clement, and Pipek, 2012), participatory development (De Angeli, Bordin, \& Blanco, 2014), or "public design" (Teli, Bordin, Menendez Blanco, Orabona, \& De Angeli, 2015), allow getting PD out of the workplace, its original main locus of research, to work in the wider social domain. Public design, in particular, starts with the concerns of people for their everyday life to promote their emergence as an organized collective sharing information and collaborative action, in an open-ended design process (Teli et al., 2015). Due to the open-ended nature of co-design, PD, and public design, the technological objectives indicated here are going to act as elements participating to the design process as sensitizing concepts, not as design choices already made.

In relation to Participatory Design, Public Design promotes the enlargement of the design space from the workplace to the public dimension. Moreover, in relation to existing public design projects (like the ones conducted by Di Salvo and colleagues already cited), PIE News has the ambition to engage in a large-scale, multi-lingual and international design process, starting with the locations of the specific pilots but not 
limited to them. In relation to the larger field of HCI, the public design approach promoted here goes beyond the attention toward vulnerable populations, like homeless (Woelfer, Iverson, Hendry, Friedman, \& Gill, 2011) to actually sustain the formation of a recursive public able to gain long-term sustainability (Teli et al., 2015).

\section{Practical strategy}

Given the objective of fostering commonfare emergence by connecting new poor and relevant stakeholders, "informing" "sharing" and "supporting" are the three specific objectives (Figure 1) to be achieved through a comprehensive approach that will benefit from the complementarity among the partner organizations, beginning with the civil society organizations that have domain knowledge and networks to be mobilized.

In a commonfare perspective, the three specific objectives begin with the new poor and connect them to the relevant stakeholders, improving the capabilities for distributed interventions not only by individuals but also by domain organizations.

\section{Consortium and funding}

The design approach used by the PIE News consortium, together with the involvement of three civil society organizations like BIN (Basic Income Network, Italy), CMS (Center for Peace Studies, Croatia), and Daniela Paes Leão \& Merel Willemsen acting for the art project MDC (Museu da Crise, Netherlands), is what makes the PIE News deeply user-driven. BIN, CMS and MDC have domain knowledge, local networks to be mobilized and a high level of motivation to do it at its best. Therefore, the three partners represent the pulsating core of PIE News by supporting full involvement of the three pilots' people in continuous design, adoption and evaluation.

On the technical side three other partners take care of the Community Awareness Platform, the Digital Currency System, and the Reputation System. They are CREATENET FBK (Italy), Dyne (Netherlands) and Abertay University (UK), that will work in collaboration with the University of Trento (Italy) in the role of design - and project coordinator, and with the Madeira Interactive Technologies Institute (M-ITI, Portugal) as research and innovation coordinator. 


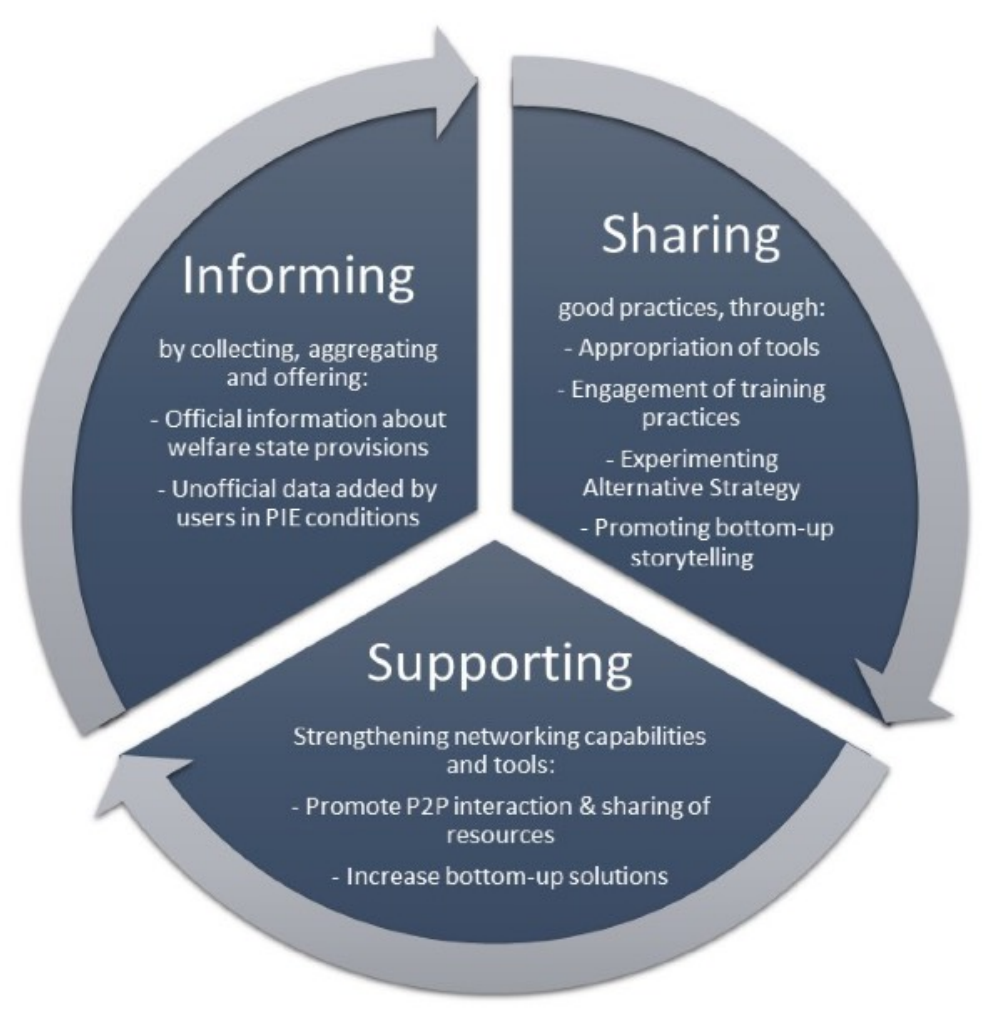

Figure 1: PIE News specific objectives

\section{Technological approach and building blocks}

In spite of the economic barriers to access, $49 \%$ of the lower-income people are regular internet users (Eurostat, 2014). A clickstream based study has actually shown that people in PIE conditions indeed use the web more than others, looking for information about employment, career and services (Martens \& Pantea, 2013). This scenario suggests that there is a wide number of PIE people having not only the skills and the means, but also the motivation to become part of this project for a concrete improvement of life conditions.

Due to the open-ended nature of the co-design approach adopted, public design, some key decisions about the technological Community Awareness Platforms (CAP) are taken with the relevant groups and based on the pilot outcomes. Nevertheless, it is already possible to identify the key components that have a high degree of probability of being included in the PIE News platform. This is possible considering the PIE News objectives of informing, sharing, and supporting, in combination with the existing technological tools that provide such capabilities. To summarize, we can foresee the public design and implementation of the following core elements:

1. PIE News Information Hub: the organized provision of information on welfare state provisions and other opportunities (training, mobility, etc.);

2. PIE News Stories Hub: the organized collection of existing stories and tools to facilitate the production and upload of new stories; 
3. PIE News Networking Hub: the organized collection of networking tools, each one well described and open to incremental improvement via people intervention.

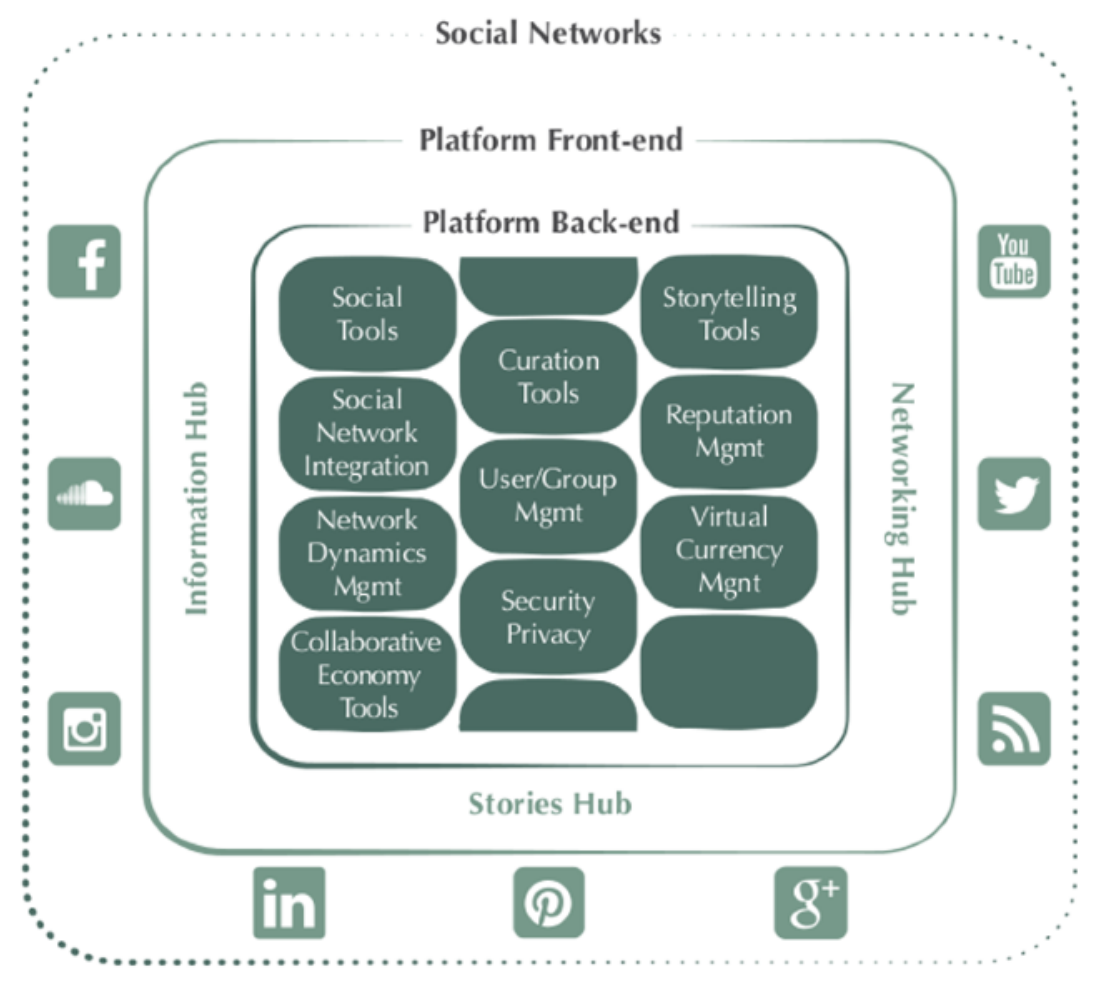

Figure 2: PIE News technological approach

Figure 2 highlights the main functional elements that PIE News as a digital platform will provide. This will represent the reference functional architecture and it will be the background for the implementation of the technical solutions during the project lifecycle. From an architectural perspective, PIE News technical solution will be composed according to three main layers:

1. External Social Networks are the main channels in order to trigger user engagement. They complement the platform in order to forge effective communication channels and foster the setup of relationships with target users and with all the relevant stakeholders. PIE News platform will structure itself as a social network supporting concerned publics at local level, fostering the bottom-up emergence of a European public.

2. Front-end: PIE News platform will also provide a dedicated web portal responsive for mobile use, whose front-end will be structured according to the following main components, the PIE News Information, Stories, and Networking Hubs.

3. Backend services of PIE News platform will provide core services needed to support users in the access and interaction with the platform, and more specifically: curation tools, storytelling tools, collaborative economy tools, social tools, users and groups management, security and privacy, reputation 
system, digital currency management, network dynamics management, and further others.

The design principles that are followed for building the technical solution can be summarized as follows:

1. Maximization of reuse of existing external services and open source components;

2. Usage of "responsive design" to maximize multi-channel access to the platform;

3. "Privacy-by-design" in order to address privacy issues in a systematic way;

4. Perform technical components selection and integration to guarantee scalability of the platform to a large users' base;

5. Address horizontal multilingual support and translation capabilities in order to support and facilitate both user participation at the local level and content internationalization (passing through English language).

The core modules of the platform for reaching a concrete participation of users and enhancing a new form of collaborative economy are the Reputation system, the Digital Currency system, and the Network Dynamics system.

\section{Reputation system}

PIE News conducts research on the use of reputation and reputation systems as social mechanisms able to support engagement, collective action and offer incentives for participation (Dellarocas, 2003). In social media projects, reputation can trigger what Farmer and Glass (2010) call the "reputation virtuous circle": people receive reputational rewards for their participation and production of good quality content and this in turn triggers strong motivation for participation and increases the likelihood of attracting new participants.

A key assumption of PIE News is that the real challenge for fostering participation of people in CAPS platforms does not lie in the creation of novel algorithms or novel interface representation of reputation. Rather, the challenge is to use existing models in line with what are the user needs (e.g. Farmer \& Glass, 2010; Jøsang, Ismail, \& Boyd, 2007). Therefore, by coupling direct participation of the user in the design process together with the adoption of reliable models will support the scalability of a CAPS project. For PIE News, we rely on a similar strategy, by using well established reputation metrics and interface solutions such as simple and direct feedbacks and their aggregation (average value). This approach has also the advantage that the users are able to use well-known and established interface patterns. One project task is devoted to the identification of appropriate existing models to be used in PIE News, for example to promote the upload of stories, their rating, their translation in different languages, or their curation in thematic folders. In line with the perspective of the public design approach (Teli et al., 2015), we work alongside the users in the co-design of the reputation systems for PIE News. 


\section{Digital currency}

The PIE News Digital Currency is a useful tool to better implement the access to basic social services, first of all to a minimum income. We face a lot of examples which testify the relevant role played by complementary currencies in many parts of Europe, especially in the phase of circulation (see Wir in Switzerland, Sardex in Sardinia, Italy, just to quote the most well-known). But only a few are able to build up a monetary circuit from the beginning to the end: starting from the finance role, as way to support local investment activities (i.e. to increase the quality of life in a given territory) to the finance of direct and indirect income till the possibility to spend the complementary currency in participating shops and in purchasing public services (like transport).

As a starting point, PIE News will implement an income via the PIE News Digital Currency in two ways: (1) to give each PIE News member a periodical amount of digital tokens (basic income); (2) to harness the storytelling capabilities of pilot participants (reward for labour). In both cases, the digital tokens can be spent on the Networking Hub of the PIE News platform. In either cases, tokens will then circulate as a form of welfare gained through a knowledge co-creation process on a Collective Awareness Platform.

From a theoretical perspective, the idea to experiment in the design of complementary currencies represents an increase in the possibilities to frame the features of a means of payment in new and innovative ways. On the one hand, conventional money is mere bank debt bearing a positive interest. On the other hand, what we call complementary currency (Lietaer, Arnspenger, Groener, \& Brunnhuber, 2012) are all the design alternatives to the conventional blueprint: interest-free, negative-interest/demurrage currencies, time currencies, social-purpose currencies and their crypto-currency counterparts are all examples of design variations from the main template: debt at positive compounded interest.

\section{Network Dynamics}

PIE News Network Dynamics tools can be used to boost the operational properties of the PIE News platform using complex networks technology. A crucial aspect for the platform is to engage users' participation: this in turn requires the users to be active on the platform, to produce contents and to engage with each other and with social groups across the various pilots. In particular, there is a key aspect related to user's participation: the evolution of the topology of the PIE News network.

The platform owner has therefore the possibility to perform actions which engender users' engagement and participation, e.g., by acceleration, that is by prioritizing the visualization of specific contents. All social media platforms possess a critical point of activation: below a threshold of engagement of users onto the system, the platform operations become critical, e.g., the platform may become not sustainable economically or it may fail to provide global connectivity or to diffuse information among the involved social groups timely and efficiently. To this respect, it is possible to leverage on imitation processes and to model them using evolutionary game theory to predict the 
effect of certain actions involving the platform users and, more important, to predict where the resources should be allocated the most in order to reach above the threshold activation level.

Activation of PIE News users, i.e., the process of engaging them onto the platform dynamics, will permit reaching for a critical mass which can let the system develop over time and grow to a global scale, e.g., the national or even the EU level. There are several mechanisms that we can leverage in order to permit such an uptake, like incentive design of user engagement tools (Chahin, Widi, El-Azouzi, De Pellegrini, \& Walrand, 2013) and cooperative schemes for online advertisement (Maggi, 2014).

\section{Design and pilots}

Leveraging on the Public Design methodology, the PIE News Design and Implementation cycles (Figure 3) is enhanced by the following tools: (a) workshops with pilots' leaders and subsequent specific pilots design activity (the PIE News Design Workshops - DWS); (b) mock-ups as outcome of the local design activities; (c) Software releases informed by mock-ups, and (d) evaluation reports as investigation of users' technological experience.

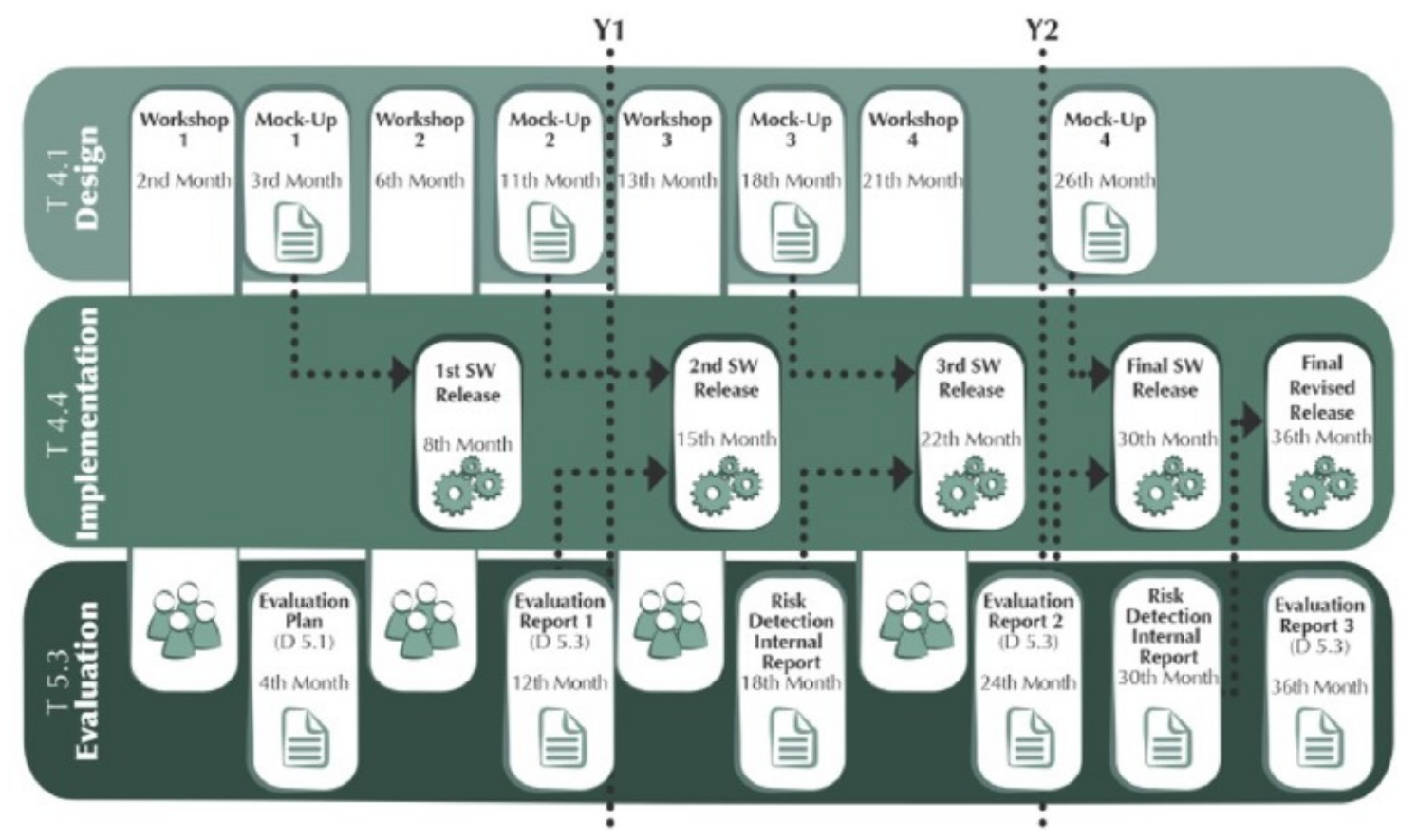

Figure 3: PIE News design and implementation approach

Five iterative cycles are planned to involve the Design, Implementation and Evaluation tasks: 
1. Basic architecture design and information: starting from the workshop 1 the project has been presented to local communities and the first early requirements have been gathered with the help of future platform users. Accordingly, the first platform mock-up and release has been generated.

2. Advanced distributed storytelling functionalities in the pilot sites: starting with the workshop 2 the advanced storytelling tools are being co-constructed with users, with subsequent generation of the second platform mock-up and release.

3. Design of currency and reputation and basic collaborative economy: starting with the workshop 3 both reputation system and the early stage of the collaborative economy functionality will be shaped with the help of users, allowing the creation of the third mock-up and release.

4. Advanced collaborative economy and sustainability: the workshop 4 will open a period of participatory investigation on improving the collaborative economy functionality, trying also to increase the sustainability of the platform. This will produce the ford mock-up and the final release of the platform.

5. Platform improvement: a final cycle of work with users will help the consortium generating a final revised release of the PIE News platform.

The project objective is to concretely involve 240 and 450 users respectively in design in evaluation activities. The evaluation approach plays a crucial role in PIE News, in fact complementing design activities with a cyclic and continuous analysis of: involved off-line networks/communities, users and stakeholders' evaluation of technological solutions, and PIE News on-line activity.

During the second year of the project an "Evaluation Dashboard" will be published and updated online in order to share with users the main evaluation results. Even if feedback-improvement cycles will be continuous during the PIE News timeline, the evaluation process will produce three yearly "Evaluation Reports" as macro evaluation reviews and two "Risk Detection Internal Reports" in order to informally create awareness in the consortium on possible issues affecting project activities.

The PIE News continuous evaluation adopts on the following tools:

1. online: platform web logs/analytics, PIE News Network Dynamics analysis, PIE News Networking Event analysis;

2. offline: focus groups, questionnaires. Offline analysis will mainly leverage on focus groups involving pilot's partners, which constitute an essential gateway to platform users and stakeholders, during PIE News Design Workshops. 


\section{Scenarios}

\section{Scenario I}

Carlo, a self-employed artist, finds himself in line at the local food bank. It had never been easy for him to make ends meet, but lately it seemed virtually impossible. The cuts in cultural funding over the previous years had a distressing effect on his standard of living. Knowing that the number of households that depend on the food bank increased by a staggering $30 \%$ over the past year made Carlo feel a little less ashamed. That and the fact that he was in good company: next in line were an architect and a journalist. They started talking and at some point the journalist asked the others if they had heard of the PIE News Platform.

Carlo's curiosity was aroused and at home he got behind his laptop and searched the project the journalist had been speaking of. After a simple registration process and a few clicks, he stumbled upon a story from a fellow artist in a similar situation. In a short video she explains how she and a few others have set up a ride sharing initiative and invites locals to participate. He gives a high rating to the video, as he found it very instructive. In another story, a man from Ukraine demonstrates how to recognize edible mushrooms and how to preserve them for later consumption. Not particularly interested in mushrooms, Carlo clicks on to discover a series of links to financial aid provisions in his city; some provisions he had never even heard of. Then his eye is drawn to the upper corner. Next to his profile picture he sees an icon that looks like a currency symbol. He discovers that he was awarded 50 PIES for supporting the ride sharing initiative and would monthly receive 500 PIES just for being active on the platform.

A few weeks later Carlo is on his way to participate in one of the PIE News Networking Events, including art foundations as participants. He figured that if he could update his website with his latest projects, it might result in a new commission. He exchanged his PIES for the workshop and the ride. He is in the car with two others: a consultant and a carpenter. They started talking and at some point the carpenter asks...

\section{Scenario II}

Helena has been active on the PIE News platform for almost a year. She is a single mother with two kids. She has met some nice people in her neighbourhood through the platform with whom she sometimes shares a nice meal and good conversation. She has commented on a few stories and also uploaded some of her own. Most of her stories deal with providing kids with warm and comfortable clothes at low costs; a strategy she has mastered by necessity over the past few years.

Her neighbour is also a single mother, raising a five-year-old daughter. Every other day the girl plays at her house in the afternoon because her mother is at work. Sometimes in the afternoon she, her kids and the girl take the dog of an elderly lady living across the street for a walk at the beach and do some grocery shopping for her on the way home. Helena isn't financially compensated for her neighbourly services, nor does she expect 
to be, even though it is at times hard for her not to compare her contributions to a liveable neighbourhood with the effectiveness of those actions by well-paid officials.

At the PIE Platform Helena receives 500 PIES unconditionally each month that she can spend either way she sees fit. This motivates her to do not only the things she is supposed to do for a reward, such as sharing and voting, but also to discover some completely new and unforeseen ways to support the PIE community, similar to what she is doing in her own neighbourhood.

\section{The sustainability challenge}

The open problems to achieve a full sustainability of the model, that will be explicitly addressed by the PIE News consortium within a specific project task, are: 1) to provide an institutional guarantee for the circulation of the PIE News Digital Currency, something that will be investigated starting with the supporting municipalities; 2) to sign an agreement with the governance institutions (municipality, category associations, trade unions, entrepreneur associations, financial institutions...) to coordinate the emission and redeem of the PIE News Digital Currency. This value chain is strictly correlated to the PIE News project, since that aims at supplementing the actual welfare state towards the commonfare, supporting PIE News sustainability.

Figure 4 represents the "commonfare" social hypothesis that is promoted by the PIE News project. As for every complementary currency system, also the PIE News Digital Currency will act in parallel - as a complement to - the conventional money that individuals experiencing PIE conditions are already able to acquire. In general, a complementary currency takes root when a group of people decides to use something as a means of payment alongside conventional bank debt as a result of lack of performance of the latter. When incentive mechanisms are put in place that sustain the various bridges among unused resources and unmet needs of the members of the group, then a complementary currency circuit is running optimally.

For all these reasons, the consortium is confident that relevant stakeholders can be convinced to sustain PIE News Digital Currency. 


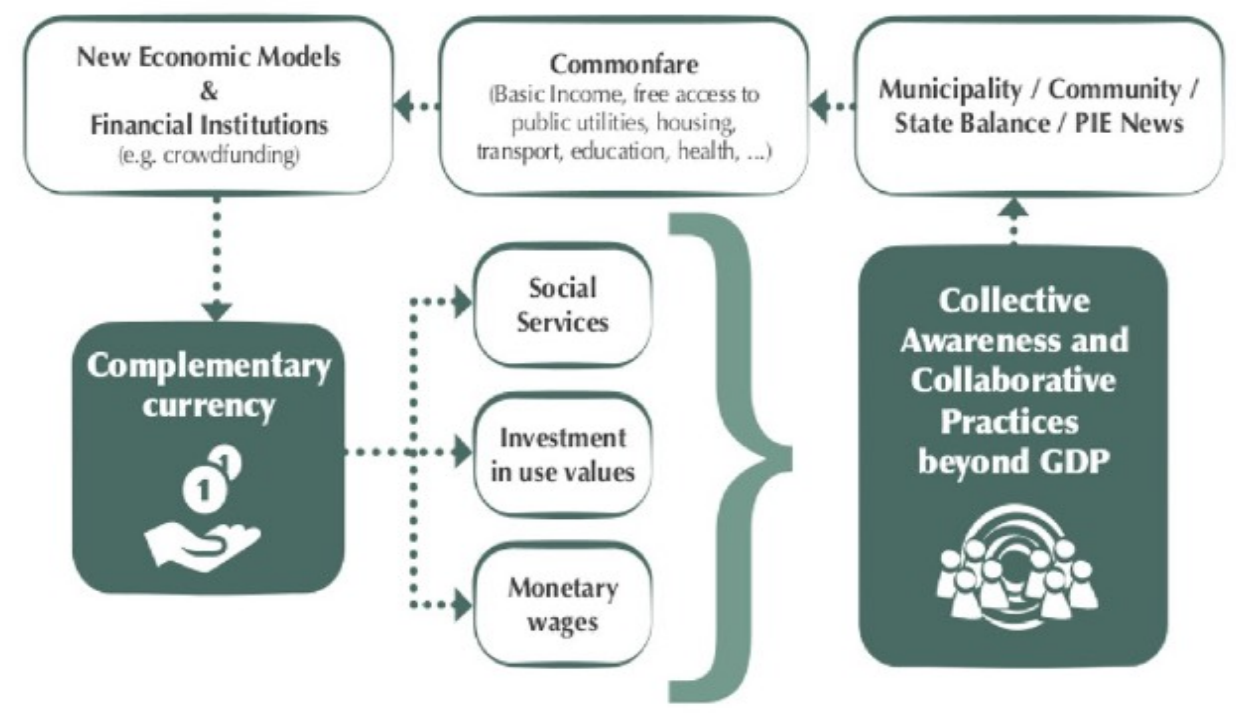

Figure 4: The PIE News social hypothesis on commonfare

Participants from all three pilots in Italy, Croatia and the Netherlands will be endowed with access to the PIE News Digital Currency and they will be allowed to spend the currency created endogenously within the platform. However, in Italy and the Netherlands, the experimentation will go further as the plan is to involve local authorities both in Milan and the pilot cities in the Netherlands. This strategy suggests the relevance of relating to existing institutions in order to promote sustainability for collaborative projects, in particular to sustain the economic basis of existing collaborations.

The main weakness of PIE News is to consider only new poor who are internet users. Unfortunately, the collective awareness platforms framework places technology at the center of a social problem resolution and it is difficult to include people without internet connection in this activity. Nevertheless, we should consider that: (a) our local networks are also purely social and associations on the territory work also with no-internet users; (b) a project "risk detection" activity will monitor technology illiteracy and internet limited access of target groups, trying to find solutions like organizing training sessions and suggesting pilots to engage in collaboration with public libraries, bars, and community centers that offer free wifi and computers; (c) unemployed and precarious workers are very often smartphone users (Eurostat, 2014); (d) it is reasonable to consider a future gradual reduction of the digital divide.

\section{Core early activities and results of PIE News year 1}

Between the many tasks, activities and results of PIE News in its first year (July 2016 June 2017) some specific issues deserve to be highlighted. First, piloting activities should be underlined, but relevant issues have been developed also on the communication, research, design and development sides of the project. 
In terms of grassroots activities, between October 2016 and March 2017 the pilot leaders involved 235 people in Croatia, Italy and The Netherlands, organizing 20 focusgroups, identifying 29 good practices to be considered within the project and developing the first 67 welfare cards to populate the first informational block of the platform. Each pilot country also started informing a wider number of people about project activities and started monitoring institutional sources to update scenario data about every six months (poverty, income, unemployment, etc.).

\section{Thinking back the communication style}

One of the first issues handled by project partners regards how to interact with people at the pilot level and online in general. Piloting partners oversee face-to-face communication (together with online tools like website, platform and Facebook page) and the PIE News approach aims to empower grassroots institution (like BIN, MDC and CMS are) following the Action Research guidelines that inspired the Participatory Design methodology.

After 6 months from the project start, based on feedbacks from the grassroots level, the consortium decided to change the project communication style as follows:

1. Hide the "PIE News" label (except for institutional communication with the European commission and some scientific activities) in favour of "Commonfare", because of a problem of homonymy and because the labelling was rejected by the people participating to our empirical research. This impacted on the already-implemented visual ID, projects website and templates, flyers and promotion material in general.

2. Furthermore, it has been decided to call what we do simply "Commonfare" and not "commonfare.net" because, even if the online platform is - formally - the core element of the project, strategically thinking it is much more important to underline the social dimension of project activities. To participants it would sound like "we are working with you while technology is just a tool".

3. Reflect on the terminology in use at the front-end (by pilot leaders with pilot people), where economy-centric and technicalities are banned, and try to adopt it also for the back-end of the project. This will probably complicate the project and research activities, but it clarifies how the bottom-up dimension is relevant for us.

At the end of the first year, the bottom-up request to find new language to describe what we are working on together with people, pointed to the need of redefine the project language and to build a shared glossary.

\section{The Commonfare glossary}

During the design phase of PIE News project the need to have a common glossary among partners emerged. A good plan of communication and a general agreement about 
the main terms at the basis of the project are necessary elements for the success of the cooperation and of the project itself.

Given the sensitivity and the extent of the themes faced by PIE News, the consortium started developing a glossary in order to identify the most recurrent terms that are open to different interpretations and to find definitions that could represent all the sensibilities of the consortium. In particular, the idea was to build each definition through a participatory approach, giving all the partners the possibility to provide their point of view about the selected issues and combining the different contributions.

The participatory approach at the basis of the glossary construction has been developed through a Wiki where project partners can collaboratively agree on the best terms to be used in the back and front-end of the project. The partners decided to develop a limited wiki in order to limit the access only to the members of the consortium through specific accounts. The admin of the wiki provided the users a selection of terms with the relative first drafts of definition, then all the process continues spontaneously.

Commonfare glossary may be seen first of all as a tool that fosters the communication among partners, because it involves a regular confrontation between them. Secondly, it represents an occasion to construct meanings and to reinforce the shared values and ideas at the basis of PIE News. Finally, the glossary underlines the importance of the language as a means to align the actions of the partners.

Some early terms on which the PIE News communication is being concentrating are: advocacy groups, basic income, commonfare, commonshare community, digital currency, labor, participation, poverty, precarious, reputation, solidarity, stakeholder, stigmatization, story, subjectivity, user.

\section{Design activities and the first release of the Platform}

A complex process of participatory design has been activated from September 2016, with a recursive process of (1) creation of the first concepts and ideas for the informative section of the Commonfare.net platform, and (2) the involvement of people at the pilot level for mock-ups evaluation and the identification of new issues to be considered within the process. This helped the technical team delivering the first release of the platform (Figure 5) at the end of February 2017, basically a simple architecture with some contents constituting the first idea for the Commonfare Info Hub. 


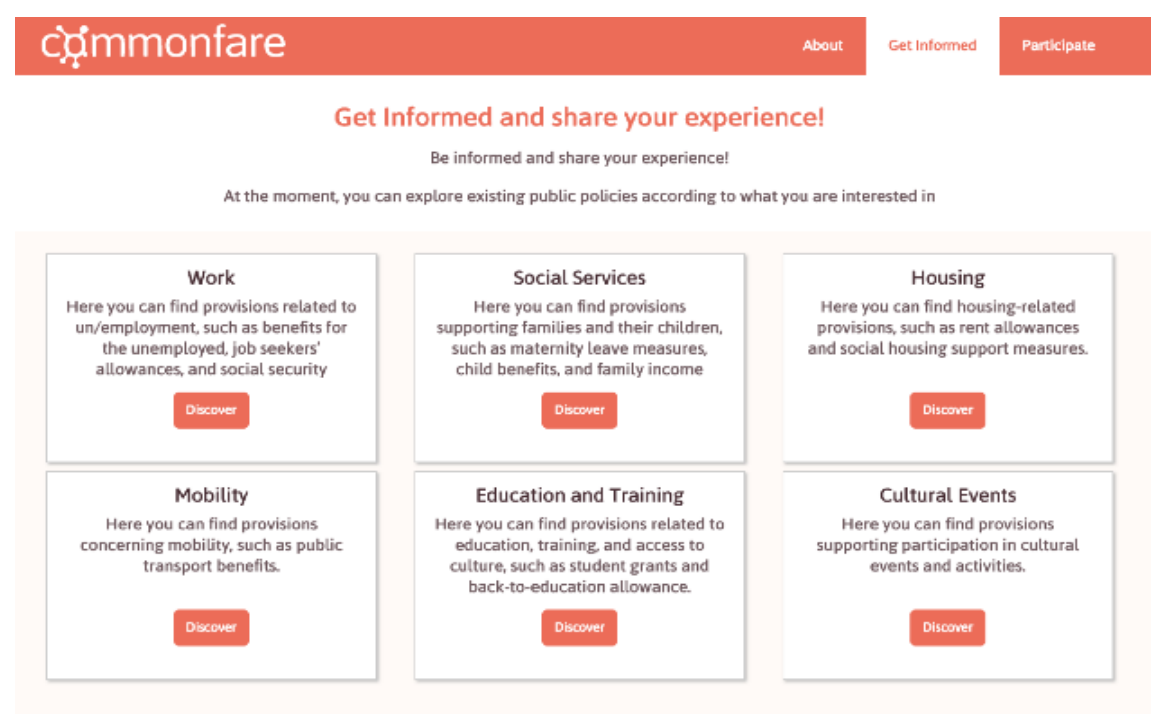

Figure 5: the first "information" release of the Commonfare.net platform.

Leveraging on the first release of the platform, pilot partners started working with local people in order to improve the "information hub", especially for the accessibility of the content, and start shaping the "storytelling hub". Actually the idea is to find the best equilibrium of social network functionalities and visualization solutions. The intent is to conduct activities with participants at each of the pilot sites to inform and shape the design of commonfare.net, regarding the role of stories and how they are designed.

In the meantime the research side of the project is working in order to rethink the reputation system - guarantying user anonymity - in connection network dynamics analysis, and a digital economy module with very rich social wallet functionalities. In all the activities, as shown by the glossary, one of the most challenging efforts is to coordinate partners with such a diverse background while maintaining and improving the level of participation and engagement on the field.

\section{Acknowledgements}

The research presented in this paper is supported by the European Community within the H2020-ICT-2015 Program (nr.: 687922).

\section{References}

Bauman, Z. (2004). Work, consumerism and the new poor. Berkshire, McGrew-Hill International.

Cantillon, B. (2011). The paradox of the social investment state: growth, employment and poverty in the Lisbon era. Journal of European Social Policy, 21(5), 432-449.

Chahin, W., Widi, H.B., El-Azouzi, R., De Pellegrini, F. \& Walrand, J. (2013). Incentive mechanisms based on minority games in heterogeneous DTNs. Proceedings from Teletraffic Confress (ICT). Shanghai: IEEE. 
De Angeli, A., Bordin, S. \& Blanco, M. (2014). Infrastructuring participatory development in information technology. Proceedings of the 13th Participatory Design Conference (1), 11-20. New York, ACM.

Dellarocas, C. (2003). The digitalization of word of mouth: promise and challenges of online feedback mechanisms. Management science, 49(10), 1407-1424.

DiSalvo, C., Clement, A., \& Pipek, V. (2012). Chapter 8: Communities: Participatory design for, with and by communities. In J. Simonsen \& T. Robertson (Eds.), Routledge international handbook of participatory design (182-210). Oxford: Routledge.

Eurofound. (2012). NEETs - Young people not in employment, education or training: characteristics, costs and policy responses in Europe. Luxembourg, Publication office of the European Union.

Eurostat. (2014). Europe 2020 indicators - poverty and social exclusion. Retrieved from: http:// ec.europa.eu/eurostat/statistics-explained/index.php/Europe_2020_indicators_poverty_and_social_exclusion

Eurostat. (2014). Information society statistics at regional level. Retrieved from: http:// ec.europa.eu/eurostat/statistics-explained/index.php/ Information_society_statistics_at_regional_level

Eurostat. (2015). Severe material deprivation rate: percentage of total population. Retrieved from: http://appsso.eurostat.ec.europa.eu/nui/show.do?dataset=ilc_mddd11\&lang=en

Eurostat. (2015). Smarter, greener, more inclusive? Indicators to support the Europe 2020 strategy. Luxembourg, Publications Office of the European Union.

Farmer, R., \& Glass, B. (2010). Building web reputation systems. O'Reilly Media. Sebastopol: CA.

Fraser, N., Gutierrez, R., \& Pena-Casas, R. (2011). Working poverty in Europe. Palgrave Macmillan. Retrieved from: http://www.palgraveconnect.com/pc/doifinder/ $10.1057 / 9780230307599$.

Fumagalli, A. (2008) Trasformazione del lavoro e trasformazioni del welfare: precarietà e welfare del comune (commonfare) in Europa. In Leon, P. and Realfonso, R. (Eds.), L'Economia della precarietà (159-174). Rome: Manifestolibri:.

Fumagalli, A. (2013). Lavoro male comune. Milano, Bruno Mondadori-Pearson Italia.

Fumagalli, A. (2015a). Cognitive, Relational (Creative) Labor and the Precarious. Movement for "Commonfare": "San Precario" and EuroMayDay". In Cocco, G., Szaniecki, B. (Eds.), Creative capitalism, multitudinous creativity. Radicalities and alterities (3-25). Maryland: Lexington Books.

Fumagalli, A. (2015b). Commonwealth, commonfare and the money of the common: The challenge to fight life subsumption. In M. B. Jorgensen \& O. G. Agustìn (Eds.), Politics of dissent (157-179). Frankfurt: Peter Lange.

Fumagalli, A., \& Lucarelli, S. (2015). "Finance, austerity and commonfare." Theory, Culture and Society, 32(7-8), 51-65.

Jøsang, A., Ismail, R., \& Boyd, C. (2007). A survey of trust and reputation systems for online service provision. Decision support systems, 43(2), 618-644.

Lietaer, B., Arnspenger, C., Groener, S. \& Brunnhuber, S. (2012). Money and Sustainability the missing link. Devon: Triarchy Press Ltd. 
Maggi, L., \& De Pellegrini, F. (2014). Cooperative online native advertisement: A game theoretical scheme leveraging on popularity dynamics. In Proceedings from 2014 IEEE DySON Workshop on Dynamic Social Networks INFOCOM. Toronto: Canada.

Martens, B., \& Pantea, S. (2013). Has the digital divide been reversed? Evidence from five EU countries. Joint Research Centre, Institute for Prospective Technological Studies.

McKay, S., Jefferys, S., Paraksevopoulou, A., and Keles, J. (2012). Study on Precarious work and social rights. Working Lives Research Institute \& London Metropolitan University. Study carried out for the European Commission (VT/2010/084). Retrieved from: http:// ec.europa.eu/social/BlobServlet?docId=7926\&langId=en

Nelson, K. (2013). Social assistance and EU poverty thresholds 1990-2008. Are European welfare systems providing just and fair protection against low income? European Sociological Review, 29(2), 386-401.

Provisional University. (2014). The Abduction of Europe III: Commonfare. Retrieved from: https://provisionaluniversity.wordpress.com/2014/03/14/the-abduction-of-europe-iiicommonfare/

Simonsen, J., \& Robertson, T. (2012). Routledge international handbook of participatory design. Oxford: Routledge.

Standing, G. (2013). The Precariat: The new dangerous class. London: Bloomsboury.

Teli, M., Bordin, S., Menendez Blanco, M., Orabona, G. and De Angeli, A. (2015). Public design of digital commons in urban places: a case study. International Journal of Human-Computer Studies, 81, 17-30.

Vercellone, C. (2014). Towards a welfare of common. Ekonomski pregled, 65(2), 194-204.

Woelfer, J.P., Iverson, A., Hendry, D.G., Friedman, B., \& Gill, B.T. (2011). Improving the safety of homeless young people with mobile phones: Values, form and function. In Proceedings of the SIGCHI Conference on Human Factors in Computing Systems (1707-1716). New York: ACM,

Zervas, G., Proserpio, D., \& Byers, J. (2015). A first look at online reputation on Airbnb, where every stay is above average. Retrieved from http://ssrn.com/abstract $=2554500$ 